
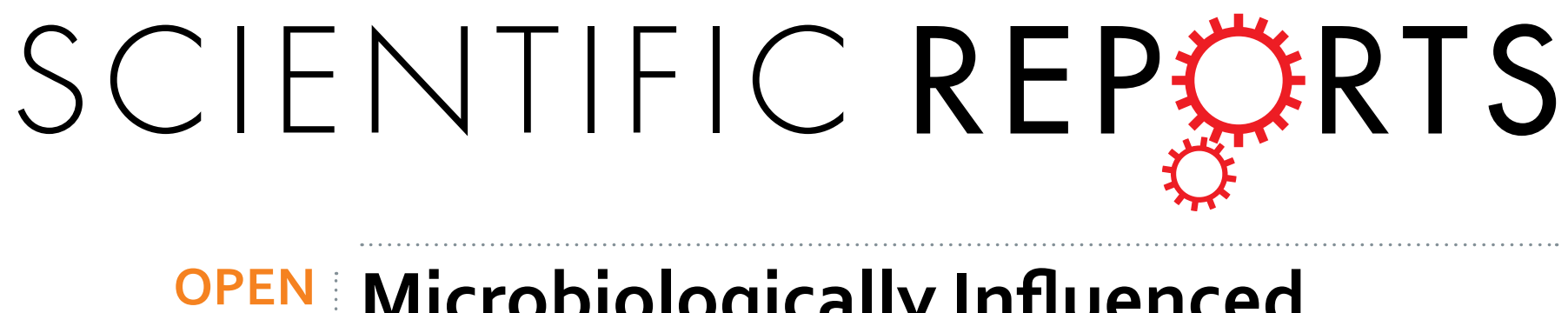

\title{
Microbiologically Influenced Corrosion of 2707 Hyper-Duplex Stainless Steel by Marine \\ Pseudomonas aeruginosa Biofilm
}

Received: 16 July 2015

Accepted: 23 December 2015

Published: 05 February 2016
Huabing $\mathrm{Li}^{1, *}$, Enze Zhou ${ }^{1, *}$, Dawei Zhang ${ }^{2}$, Dake Xu ${ }^{3}$, Jin Xia ${ }^{4}$, Chunguang Yang ${ }^{3}$, Hao Feng ${ }^{1}$, Zhouhua Jiang ${ }^{1}$, Xiaogang $\mathrm{Li}^{2}$, Tingyue $\mathrm{Gu}^{5}$ \& Ke Yang ${ }^{3}$

Microbiologically Influenced Corrosion (MIC) is a serious problem in many industries because it causes huge economic losses. Due to its excellent resistance to chemical corrosion, 2707 hyper duplex stainless steel (2707 HDSS) has been used in the marine environment. However, its resistance to MIC was not experimentally proven. In this study, the MIC behavior of 2707 HDSS caused by the marine aerobe Pseudomonas aeruginosa was investigated. Electrochemical analyses demonstrated a positive shift in the corrosion potential and an increase in the corrosion current density in the presence of the $P$. aeruginosa biofilm in the $2216 \mathrm{E}$ medium. X-ray photoelectron spectroscopy (XPS) analysis results showed a decrease in $\mathrm{Cr}$ content on the coupon surface beneath the biofilm. The pit imaging analysis showed that the $P$. aeruginosa biofilm caused a largest pit depth of $0.69 \mu \mathrm{m}$ in 14 days of incubation. Although this was quite small, it indicated that 2707 HDSS was not completely immune to MIC by the P. aeruginosa biofilm.

Duplex stainless steel (DSS) is widely used in various industries due to its desirable combination of excellent mechanical properties and corrosion resistance ${ }^{1,2}$. However, localized pitting corrosion can still occur and it affects the integrity of this kind of steel ${ }^{3,4}$. DSS is not immune to microbiologically influenced corrosion (MIC) ${ }^{5,6}$. Despite a very broad range of applications for DSS, there are still environments where the corrosion resistance of DSS is inadequate for long-term services. This means, more expensive materials with higher corrosion resistance are needed. Jeon et al. ${ }^{7}$ found that even super duplex stainless steels (SDSSs) exhibit some limits in corrosion resistance. Therefore, hyper duplex stainless steels (HDSSs) with a higher corrosion resistance are needed in some applications. This led to the development of highly alloyed HDSSs.

The corrosion resistance of DSS is determined by the ratio of the $\alpha$-phase and $\gamma$-phase and by the $\mathrm{Cr}, \mathrm{Mo}$, and $\mathrm{W}$ depleted regions that are adjacent to the secondary phases ${ }^{8-10}$. HDSS contains high levels of Cr, Mo and $\mathrm{N}^{11}$, resulting in its excellent corrosion resistance and a high value (45-50) of pitting resistance equivalent number (PREN), which is calculated from wt. $\% \mathrm{Cr}+3.3$ (wt.\% $\mathrm{Mo}+0.5 \mathrm{wt} . \% \mathrm{~W})+16 \mathrm{wt} \% \mathrm{~N}^{12}$. Its excellent corrosion resistance properties rely on a well-balanced composition with approximately $50 \%$ ferrite $(\alpha)$ and $50 \%$ austenite $(\gamma)$ phases, that offer HDSS improved mechanical properties and higher chloride corrosion resistance compared with conventional DSS ${ }^{13}$. The improved corrosion resistance extends the use of HDSS in more aggressive chloride environments, such as marine environments.

MIC is a major problem in many industries such as oil and gas, as well as water utilities ${ }^{14}$. MIC accounts for $20 \%$ of all corrosion damages ${ }^{15}$. MIC is bioelectrochemical corrosion that can be observed in many environments ${ }^{16}$. Biofilms formed on a metal surface will change the electrochemical conditions and thus influencing the corrosion processes. It is widely accepted that MIC corrosion is caused by biofilms ${ }^{14}$. Electrogenic microbes corrode metals in order to obtain maintenance energy for survival ${ }^{17}$. The most recent MIC research suggested

${ }^{1}$ School of Metallurgy, Northeastern University, Shenyang, 110819, China. ${ }^{2}$ Corrosion and Protection Center, University of Science and Technology Beijing, Beijing 100083, P. R. China. ${ }^{3}$ Institute of Metal Research, Chinese Academy of Sciences, Shenyang, 110016, China. ${ }^{4}$ College of Chemistry, Liaoning University, Shenyang, 110036, China. ${ }^{5}$ Department of Chemical and Biomolecular Engineering, Institute for Corrosion and Multiphase Technology, Ohio University, Athens, Ohio 45701, USA. *These authors contributed equally to this work. Correspondence and requests for materials should be addressed to D.X. (email: xudake@imr.ac.cn) 


\begin{tabular}{|l|c|c|c|c|c|c|c|c|c|c|c|}
\hline \multirow{2}{*}{ Material } & \multicolumn{10}{|c|}{ Element } \\
\cline { 2 - 12 } & $\mathbf{S i}$ & Mn & P & S & Co & Cr & Ni & Mo & Cu & N & Fe \\
\hline 2707 HDSS (wt.\%) & 0.42 & 1.11 & 0.005 & 0.003 & 1.00 & 26.83 & 7.14 & 4.88 & 0.98 & 0.39 & Bal. \\
\hline
\end{tabular}

Table 1. Chemical composition of 2707 HDSS.

\begin{tabular}{|l|c|c|c|}
\hline Material & Tensile strength (MPa) & Yield strength 0.2\% (MPa) & Elongation (\%) \\
\hline 2707 HDSS & 950 & 650 & 25 \\
\hline
\end{tabular}

Table 2. Mechanical properties of 2707 HDSS.

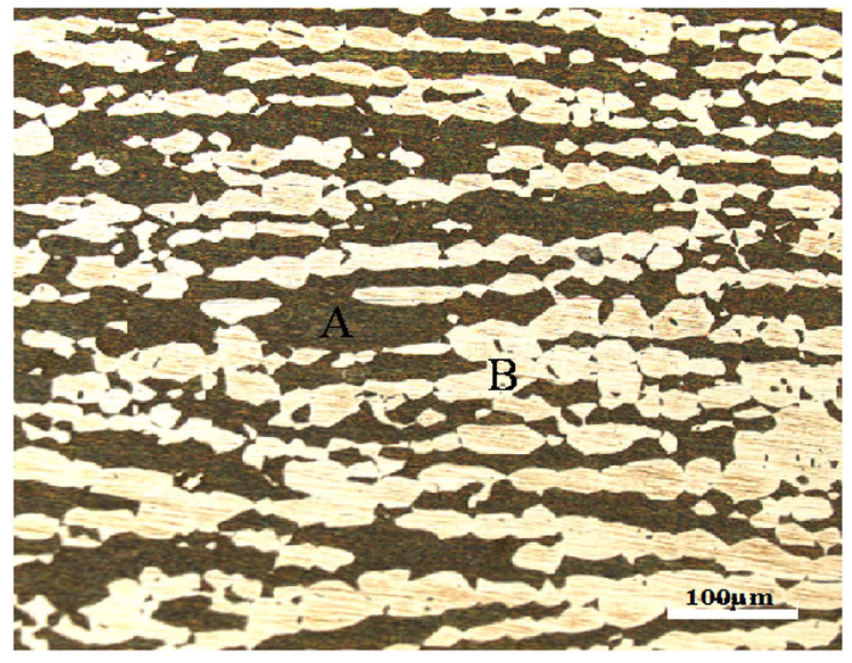

Figure 1. Microstructure of 2707 HDSS: (A) ferrite, and (B) austenite.

that EET (extracellular electron transfer) is a rate-limiting factor in MIC caused by electrogenic microbes. Zhang et al. ${ }^{18}$ demonstrated that an electron mediator accelerated the electron transfer between sessile Desulfovibrio vulgaris cells and 304 stainless steel, resulting in a much more severe MIC attack. Enning et al. ${ }^{19}$ and Venzlaff et al. ${ }^{20}$ showed that a corrosive sulfate-reducing bacterium (SRB) biofilm was capable of directly uptaking electrons from the metal matrix, resulting in serious pitting corrosion.

DSS is known to be susceptible to MIC in environments containing SRB, iron reducing bacteria (IRB), etc ${ }^{21}$. These bacteria cause localized pitting corrosion on DSS surfaces under biofilms ${ }^{22,23}$. Unlike DSS, very little is known for the MIC of HDSS ${ }^{24}$.

Pseudomonas aeruginosa is a Gram-negative motile rod bacterium widely distributed in nature ${ }^{25}$. P. aeruginosa is also a predominant group of micro-organisms in marine environments causing MIC to steels ${ }^{26}$. The genus Pseudomonas is closely involved in corrosion processes and has been recognized as the pioneer colonizer in the process of biofilm formation ${ }^{27}$. Mahat et al. ${ }^{28}$ and Yuan et al. ${ }^{29}$ demonstrated that $P$. aeruginosa has the propensity to increase the corrosion rates of mild steels and alloys in aquatic environments.

The main aim of this work was to investigate the MIC characteristics of 2707 HDSS caused by the marine aerobe $P$. aeruginosa using electrochemical methods, surface analysis techniques and corrosion product analyses. Electrochemical studies, including open circuit potential (OCP), linear polarization resistance (LPR), electrochemical impedance spectroscopy (EIS) and potential dynamic polarization were performed to study the MIC behavior of 2707 HDSS. The energy dispersive spectrometer (EDS) analysis was undertaken to find the chemical elements on the corroded surface. In addition, the X-ray photoelectron spectroscopy (XPS) analysis was used to determine the stability of the oxide film passivity under the influence of a marine environment containing $P$. aeruginosa. The pit depth was measured under a confocal laser scanning microscope (CLSM).

\section{Results}

Material characterizations. Table 1 lists the chemical composition of 2707 HDSS. Table 2 shows that 2707 HDSS has excellent mechanical properties with yield strength of $650 \mathrm{MPa}$. Figure 1 reveals the optical microstructures of the solution heat-treated 2707 HDSS. Elongated bands of austenite and ferrite phases without secondary phases can be seen in the microstructure that contains approximately $50 \%$ austenite and $50 \%$ ferrite phases.

Open circuit potential versus time. Figure 2 a shows open circuit potential $\left(\mathrm{E}_{\mathrm{ocp}}\right)$ vs. exposure time data for $2707 \mathrm{HDSS}$ in the abiotic $2216 \mathrm{E}$ medium and in the P. aeruginosa broth at $37^{\circ} \mathrm{C}$ for 14 days. It reveals that the most and significant variation in $\mathrm{E}_{\text {ocp }}$ occurred in the initial $24 \mathrm{~h}$. The $\mathrm{E}_{\text {ocp }}$ values in both cases peaked around 

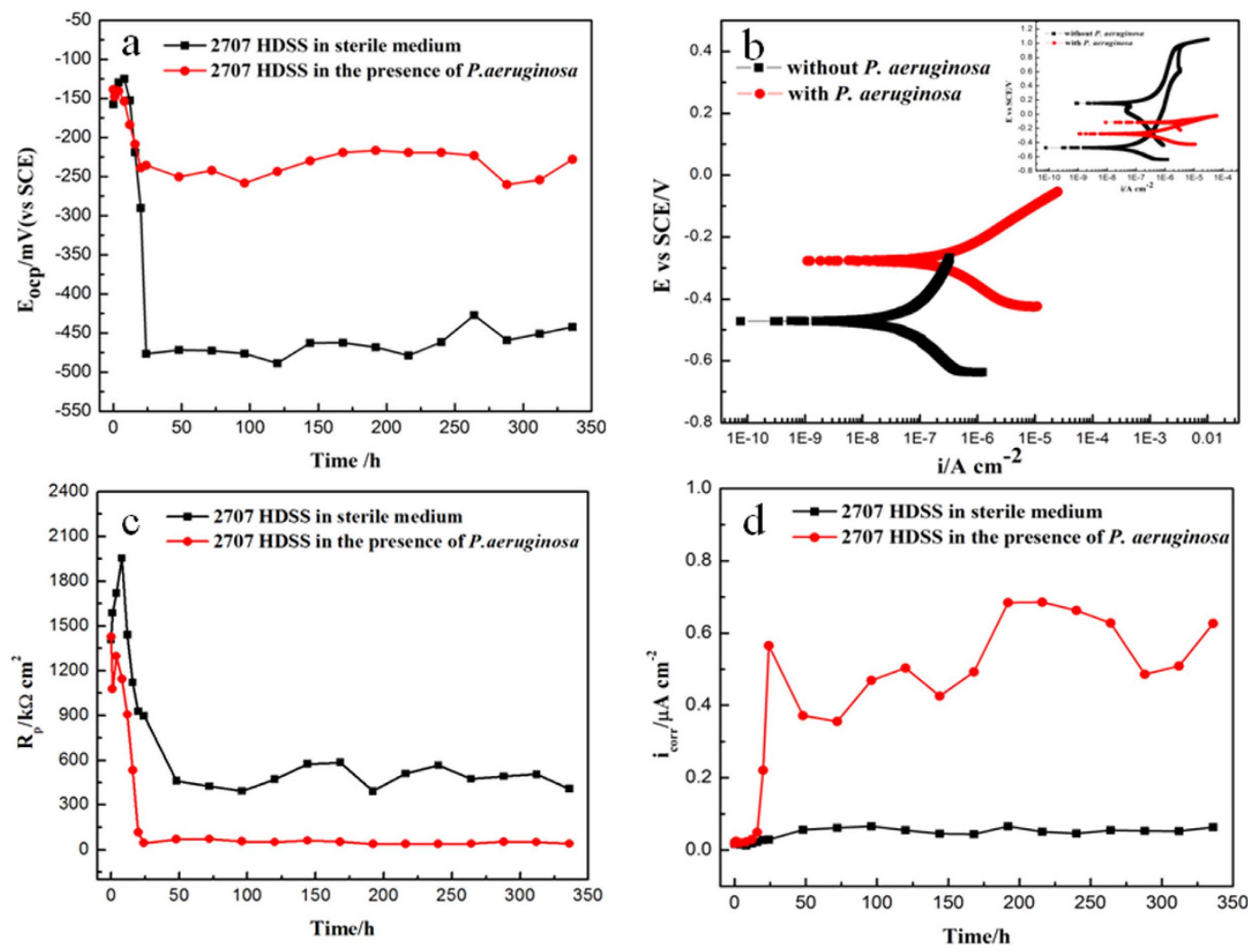

Figure 2. Electrochemical tests for 2707 HDSS coupons in the abiotic medium and in the P. aeruginosa broth at $37^{\circ} \mathrm{C}$ : (a) variation of $\mathrm{E}_{\text {ocp }}$ with exposure time, (b) polarization curves on the $14^{\text {th }}$ day, (c) variation of $\mathrm{R}_{\mathrm{p}}$ with exposure time, and (d) variation of $\mathrm{i}_{\text {corr }}$ with exposure time.

\begin{tabular}{|l|c|c|c|c|}
\hline Medium & $\mathbf{i}_{\text {corr }}\left(\mu \mathbf{A ~ c m}^{-2}\right)$ & $\mathbf{E}_{\text {corr }}(\mathbf{m V})$ & $\boldsymbol{\beta}_{\boldsymbol{a}}(\mathbf{m V} / \mathbf{d e c})$ & $\boldsymbol{\beta}_{\boldsymbol{c}}(\mathbf{m V} / \mathbf{d e c})$ \\
\hline Sterile & 0.087 & -472 & 286.4 & -237.8 \\
\hline P. aeruginosa inoculated & 0.328 & -277 & 121.2 & -153.6 \\
\hline
\end{tabular}

Table 3. The electrochemical corrosion parameters determined from the polarization curves of 2707 HDSS after 14 days of incubation at $37^{\circ} \mathrm{C}$.

$-145 \mathrm{mV}$ (vs. SCE) at about $16 \mathrm{~h}$ and then dropped sharply, reaching $-477 \mathrm{mV}$ (vs. SCE) and $-236 \mathrm{mV}$ (vs. SCE) for the abiotic coupon and the $P$. aeruginosa coupon, respectively. After $24 \mathrm{~h}$, the $\mathrm{E}_{\text {ocp }}$ value of $2707 \mathrm{HDSS}$ remained relatively stable at $-228 \mathrm{mV}$ (vs. SCE) for the $P$. aeruginosa coupon, while the corresponding value for the abiotic coupon was approximately $-442 \mathrm{mV}$ (vs. SCE). The $\mathrm{E}_{\text {ocp }}$ in the presence of $P$. aeruginosa was considerably lower.

Polarization Curves. The values of the electrochemical corrosion parameters of 2707 HDSS coupons after exposure for 14 days in the abiotic medium as well as in the P. aeruginosa inoculated medium are listed in Table 3. The tangential lines of the anodic and cathodic curves were extrapolated to reach an intersection point to yield corrosion current density $\left(\mathrm{i}_{\text {corr }}\right)$, corrosion potential $\left(\mathrm{E}_{\text {corr }}\right)$, and Tafel slopes $\left(\beta_{\alpha}\right.$ and $\left.\beta_{\mathrm{c}}\right)$ following the standard approach $^{30,31}$.

As shown in Figure $2 \mathrm{~b}$, compared with the abiotic curves, the $P$. aeruginos a curves shifted upward leading to an increase of $\mathrm{E}_{\text {corr }}$. The $\mathrm{i}_{\text {corr }}$ value, that was directly proportional to the corrosion rate, increased to $0.328 \mu \mathrm{A} \mathrm{cm}^{-2}$ for the P. aeruginosa coupon, four times greater than that for the abiotic coupon $\left(0.087 \mu \mathrm{A} \mathrm{cm}^{-2}\right)$.

Linear polarization resistance. LPR is a classical electrochemical method for fast corrosion analysis that is non-destructive. It is also used to study $\mathrm{MIC}^{32}$. Figure $2 \mathrm{c}$ shows the variation of the polarization resistance $\left(\mathrm{R}_{\mathrm{p}}\right)$ as a function of exposure time. A higher $\mathrm{R}_{\mathrm{p}}$ value means less corrosion. During the initial $24 \mathrm{~h}$, the $\mathrm{R}_{\mathrm{p}}$ of $2707 \mathrm{HDSS}$ reached a maximum value of $1955 \mathrm{k} \Omega \mathrm{cm}^{2}$ for the abiotic coupon and $1429 \mathrm{k} \Omega \mathrm{cm}^{2}$ for the P. aeruginosa coupon. Figure $2 \mathrm{c}$ also shows that the $\mathrm{R}_{\mathrm{p}}$ value fell quickly after one day and then remained relatively unchanged for the next 13 days. The $\mathrm{R}_{\mathrm{p}}$ value for the $P$. aeruginosa coupon was around $40 \mathrm{k} \Omega \mathrm{cm}^{2}$, much lower than the $450 \mathrm{k} \Omega \mathrm{cm}^{2}$ value for the abiotic coupon. 

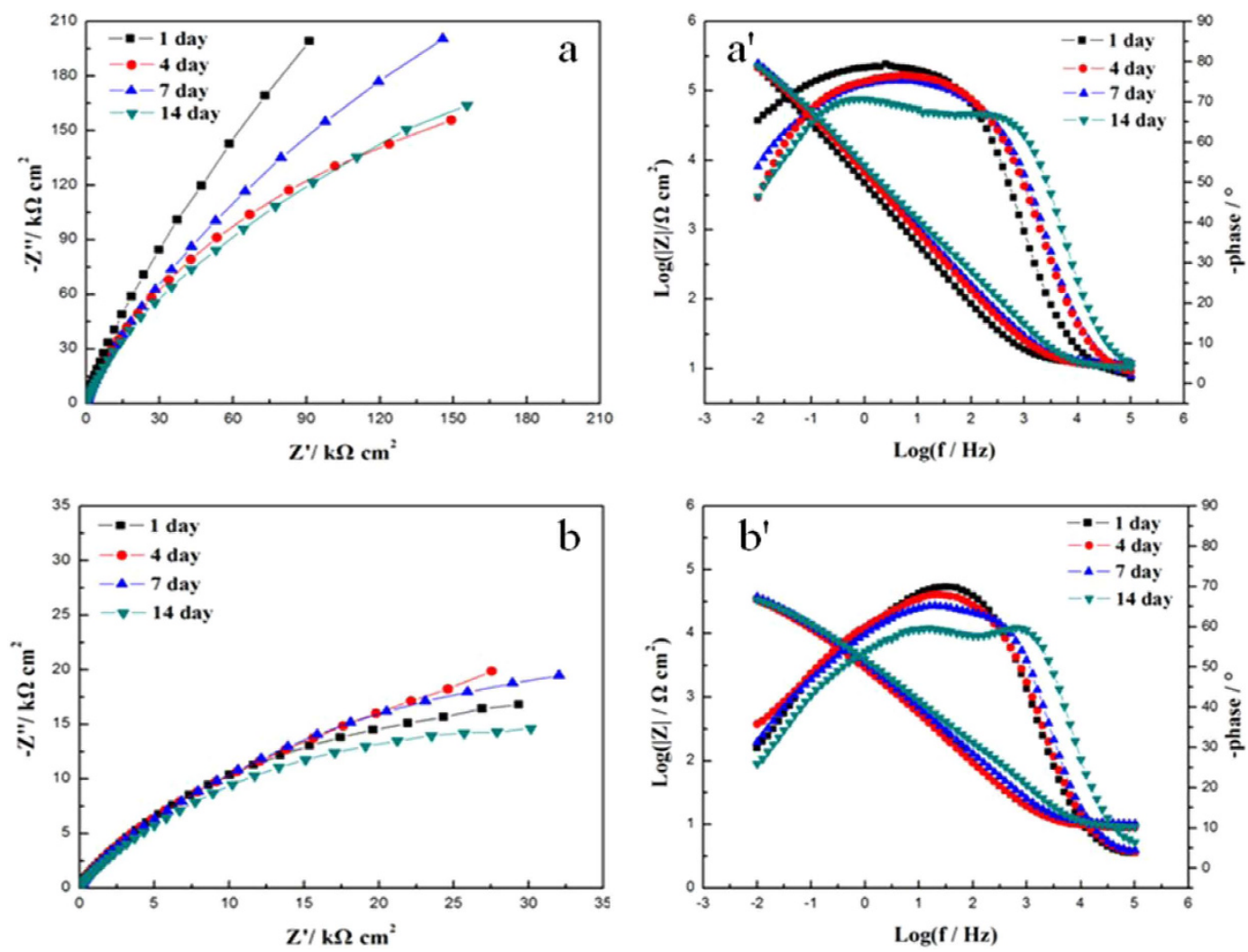

Figure 3. The Nyquist and Bode plots of 2707 HDSS coupons with and without exposure to $P$. aeruginosa: $\left(\mathbf{a}, \mathbf{a}^{\prime}\right) 2707$ HDSS in the abiotic medium, and (b,b') 2707 HDSS in the P. aeruginosa broth.

The $\mathrm{i}_{\text {corr }}$ value is directly proportional to the uniform corrosion rate. Its value can be calculated from the Stern-Geary equation below,

$$
\mathrm{i}_{\text {corr }}=\mathrm{B} / \mathrm{R}_{\mathrm{p}}
$$

Following Zou et al. ${ }^{33}$, the Tafel slope B in this work was assumed a typical value of $26 \mathrm{mV} / \mathrm{dec}$. Figure $2 \mathrm{~d}$ shows that $\mathrm{i}_{\text {corr }}$ remained relatively stable for the abiotic 2707 coupon while it fluctuated considerably for the $P$. aeruginosa coupon that had a large jump after the initial $24 \mathrm{~h}$. The $\mathrm{i}_{\text {corr }}$ value for the P. aeruginosa coupon was one order of magnitude higher than that of the abiotic control. This trend agreed with the polarization resistance result.

Electrochemical impedance spectroscopy. EIS is another nondestructive technique to characterize electrochemical reactions at a corrosion interface ${ }^{34}$. Impedance spectra and calculated capacitance values of coupons exposed to the abiotic medium and the $P$. aeruginosa solution, $\mathrm{R}_{\mathrm{b}}$ the resistance of passive film/biofilm formed on the coupon surface, $\mathrm{R}_{\mathrm{ct}}$ the charge transfer resistance, $\mathrm{C}_{\mathrm{dl}}$ the capacitance of the electrical double layer (EDL), and $\mathrm{Q}_{\mathrm{CPE}}$ the constant phase element $(\mathrm{CPE})$ parameter. These parameters were further analyzed by fitting data with an equivalent electrical circuit (EEC) model.

Figure 3 shows the typical Nyquist diagrams ( $\mathrm{a}$ and $\mathrm{b}$ ) and Bode plots $\left(\mathrm{a}^{\prime}\right.$ and $\left.\mathrm{b}^{\prime}\right)$ at different incubation times for 2707 HDSS coupons in the abiotic medium and in the P. aeruginosa broth. The diameters of the Nyquist loops decreased in the presence of $P$. aeruginosa. The Bode plot (Figure $3 \mathrm{~b}^{\prime}$ ) shows an increase of the total impedance magnitudes. The information of the relaxation time constants can be provided by the phase maxima. Figure 4 shows the physical structure and their corresponding EECs based on a single-layer (a) and a double-layer (b). $\mathrm{CPE}$ was introduced into the EEC models. Its admittance and impedance, respectively, are expressed below:

$$
\begin{gathered}
Y_{C P E}=Y_{0}(j \omega)^{n} \\
Z_{C P E}=\left(1 / Y_{0}\right)(j \omega)^{-n}
\end{gathered}
$$

where $\mathrm{Y}_{0}$ is the magnitude of the CPE, $\mathrm{j}$ the imaginary number or $(-1)^{1 / 2}, \omega$ the angular frequency, and $\mathrm{n}$ the $\mathrm{CPE}$ power index which is less than unity ${ }^{35}$. The inverse of the charge-transfer resistance (i.e., $\left.1 / R_{c t}\right)$ corresponds to the corrosion rate. A smaller $\mathrm{R}_{\mathrm{ct}}$ means a faster corrosion rate ${ }^{27}$. After 14 days of incubation, the $\mathrm{R}_{\mathrm{ct}}$ of the P. aeruginosa coupon reached $32 \mathrm{k} \Omega \mathrm{cm}^{2}$, much smaller than the $489 \mathrm{k} \Omega \mathrm{cm}^{2}$ for the abiotic coupon (Table 4). 
a
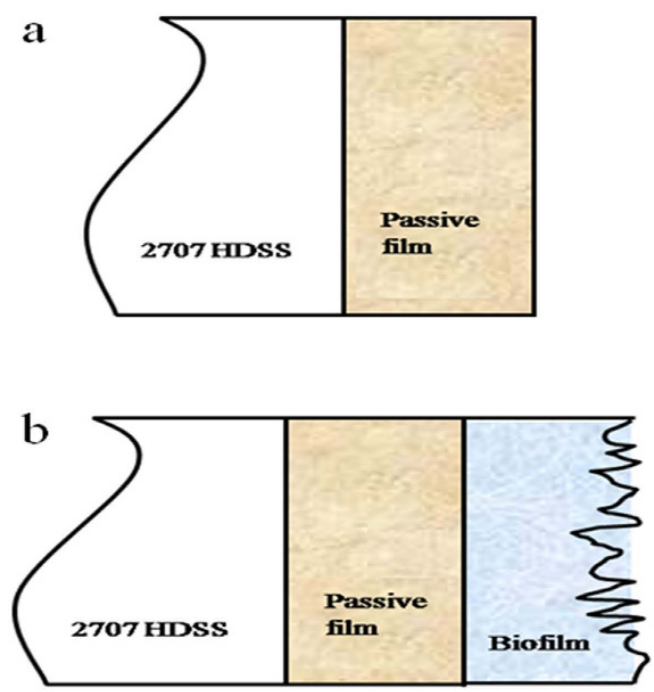

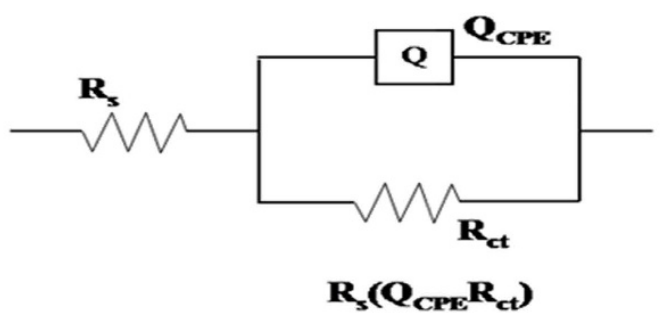

$\mathbf{R}_{\mathbf{s}}\left(\mathbf{Q}_{\mathbf{C P E}} \mathbf{R}_{\mathrm{ct}}\right)$

Figure 4. Two physical models and the corresponding equivalent circuits used for fitting the impedance spectra of 2707 HDSS coupons: (a) in the abiotic medium, and (b) in the P. aeruginosa broth.

\begin{tabular}{|l|c|c|c|c|c|c|}
\hline $\begin{array}{l}\text { Duration } \\
(\text { days })\end{array}$ & $\begin{array}{c}\mathbf{R}_{\mathrm{s}} \\
\left(\boldsymbol{\Omega} \mathbf{c m}^{2}\right)\end{array}$ & $\begin{array}{c}\mathbf{Q}_{\mathrm{CPE}} \times \mathbf{1 0}^{-\mathbf{5}} \\
\left(\boldsymbol{\Omega}^{-\mathbf{1}} \mathbf{S}^{\mathbf{n}} \mathbf{c m}^{-2}\right)\end{array}$ & $\mathbf{n}$ & $\begin{array}{c}\mathbf{R}_{\mathbf{b}} \\
\left(\mathbf{k} \boldsymbol{\Omega} \mathbf{c m}^{2}\right)\end{array}$ & $\begin{array}{c}\mathbf{C}_{\mathbf{d l}} \\
\left(\mu \mathbf{F} \mathbf{c m}^{-2}\right)\end{array}$ & $\begin{array}{c}\mathbf{R}_{\mathrm{ct}} \\
\left(\mathbf{k} \boldsymbol{\Omega} \mathbf{~ c m}^{2}\right)\end{array}$ \\
\hline 2707 HDSS in the P. aeruginosa broth \\
\hline 1 & 9.46 & 6.416 & 0.7961 & 16.48 & 168.4 & 24.9 \\
\hline 4 & 8.56 & 7.791 & 0.7702 & 21.65 & 274.6 & 29.2 \\
\hline 7 & 9.49 & 6.476 & 0.7539 & 21.68 & 185.9 & 29.1 \\
\hline 14 & 7.93 & 6.446 & 0.7016 & 24.61 & 103.1 & 32.1 \\
\hline 2707 HDSS in the abiotic medium & 11.89 & 4.360 & 0.8676 & - & - & 807.2 \\
\hline 1 & 11.01 & 3.224 & 0.8405 & - & - & 388.0 \\
\hline 4 & 11.75 & 2.979 & 0.8273 & - & - & 568.3 \\
\hline 7 & 9.56 & 2.720 & 0.7803 & - & - & 489.4 \\
\hline 14 &
\end{tabular}

Table 4. Electrochemical model impedance parameters of 2707 HDSS in the P. aeruginosa broth and in the abiotic medium.

Biofilm visualization. The CLSM images and SEM images in Figure 5 clearly indicate that the biofilm coverage on the 2707 HDSS coupon surface after 7 days was dense. However, after 14 days the biofilm coverage was sparse and some dead cells appeared. Table 5 shows the biofilm thickness on the 2707 HDSS coupon after exposure to $P$. aeruginosa for 7 and 14 days. The largest biofilm thickness changed from $23.4 \mu \mathrm{m}$ after 7 days to $18.9 \mu \mathrm{m}$ after 14 days. The average biofilm thickness also confirmed the trend. It decreased from $22.2 \pm 0.7 \mu \mathrm{m}$ after 7 days to $17.8 \pm 1.0 \mu \mathrm{m}$ after 14 days.

Chemical elements in the biofilm and corrosion products on the coupon exposed to P. aeruginosa for 14 days were revealed by EDS. Figure 6 shows the amounts of C, N, O, P in the biofilm and corrosion products were much higher than those in the bare metal because these elements were associated with the biofilm and its metabolic products. Cr and Fe are needed by microorganisms only at trace levels. The high levels of $\mathrm{Cr}$ and Fe in the biofilm and corrosion products on the coupon surface suggest loss of the elements by the metal matrix due to corrosion.

Pitting corrosion was observed with and without $P$. aeruginosa in the $2216 \mathrm{E}$ medium after 14 days. Before incubation, the coupon surfaces were smooth and had no defects (Figure 7a). After incubation and removing the biofilm and corrosion products, the deepest pits on the coupon surfaces were examined under CLSM as shown in Figure $7 \mathrm{~b}$ and c. No significant pits were found on the abiotic control coupon surface (largest pit depth $0.02 \mu \mathrm{m}$ ). The largest pit depth caused by P. aeruginosa was $0.52 \mu \mathrm{m}$ after 7 days and $0.69 \mu \mathrm{m}$ after 14 days, and the average largest pit depth based on 3 coupons (with 10 largest pit depth values per coupon selected) reached $0.42 \pm 0.12 \mu \mathrm{m}$ and $0.52 \pm 0.15 \mu \mathrm{m}$, respectively (Table 5). These pit depth values were small, but significant.

XPS analysis of 2707 HDSS coupon surfaces. Figure 8 shows the XPS spectra of different coupon surfaces, and the chemical composition of each surface analysis is summarized in Table 6. In Table 6, the atomic percentages of $\mathrm{Fe}$ and $\mathrm{Cr}$ in the presence of $P$. aeruginosa (samples $\mathrm{A}$ and $\mathrm{B}$ ) were much lower than those for the abiotic control coupons (samples $\mathrm{C}$ and D). For the P. aeruginosa coupons, the $\mathrm{Cr} 2 \mathrm{p}$ core-level spectrum was 

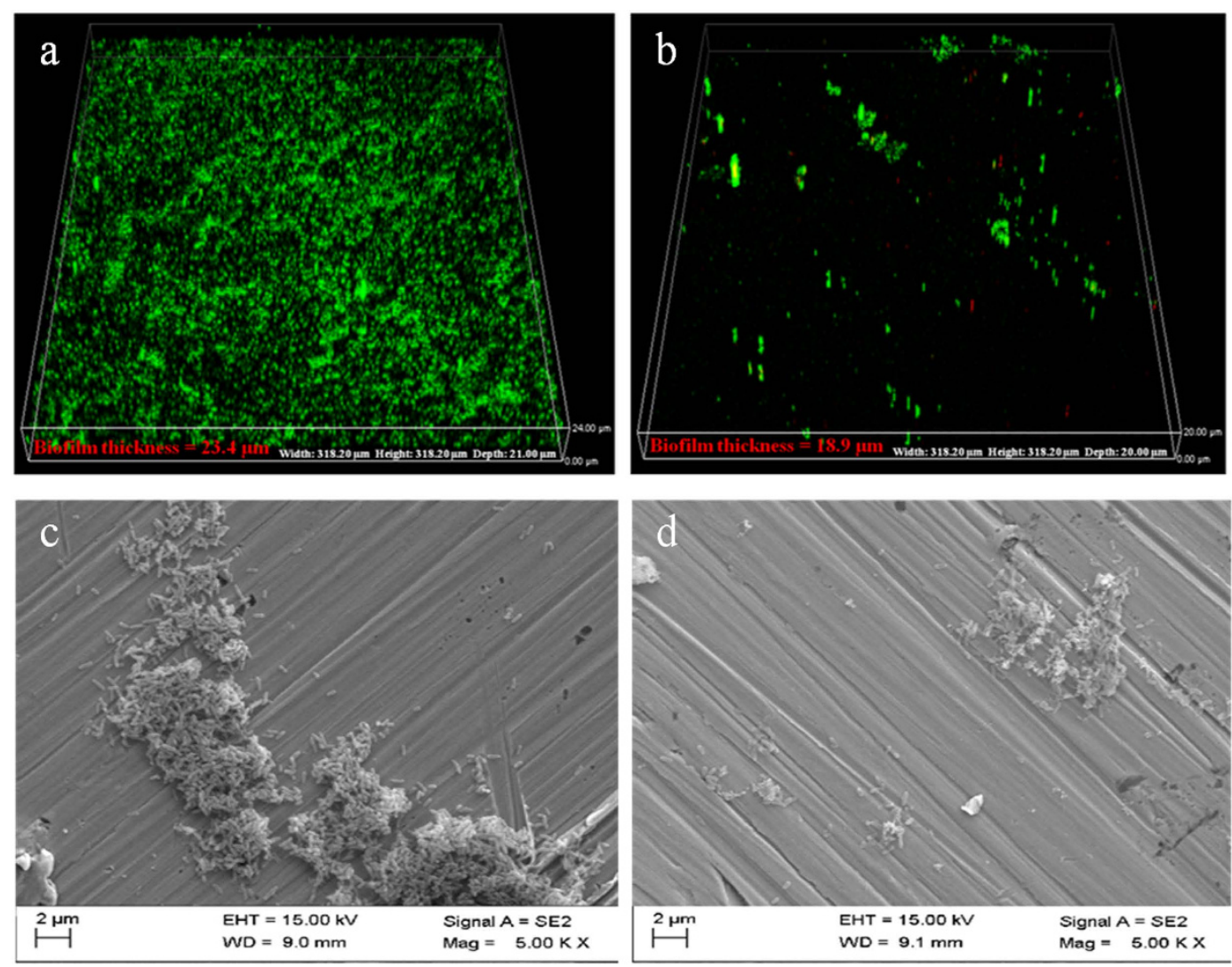

Figure 5. The morphology of $P$. aeruginosa biofilms on coupon surfaces: (a) the 3-D CLSM image after 7 days, (b) the 3-D CLSM image after 14 days, (c) the SEM image after 7 days, and (d) the SEM image after 14 days.

\begin{tabular}{|l|c|c|c|}
\hline & $\begin{array}{c}\text { abiotic } \\
\text { medium }\end{array}$ & $\begin{array}{c}\text { P. aeruginosa } \\
\text { incubated for 7 days }\end{array}$ & $\begin{array}{c}\text { P. aeruginosa } \\
\text { incubated for 14 days }\end{array}$ \\
\hline Maximum pit depth $(\mu \mathrm{m})$ & 0.02 & 0.52 & 0.69 \\
\hline Average largest pit depth $(\mu \mathrm{m})$ & $0.017 \pm 0.01$ & $0.42 \pm 0.12$ & $0.52 \pm 0.15$ \\
\hline Largest biofilm thickness $(\mu \mathrm{m})$ & - & 23.4 & 18.9 \\
\hline Average biofilm thickness $(\mu \mathrm{m})$ & - & $22.2 \pm 0.7$ & $17.8 \pm 1.0$ \\
\hline
\end{tabular}

Table 5. Pit depth and biofilm thickness of 2707 HDSS in the abiotic medium and P. aeruginosa broth.

curve-fitted into four peak components at binding energy (BE) values of 574.4, 576.6, 578.3 and 586.8 eV, which were attributable to $\mathrm{Cr}, \mathrm{Cr}_{2} \mathrm{O}_{3}, \mathrm{CrO}_{3}$ and $\mathrm{Cr}(\mathrm{OH})_{3}$, respectively (Figure $9 \mathrm{a}$ and $\mathrm{b}$ ). For the abiotic coupons, the $\mathrm{Cr}$ $2 \mathrm{p}$ core-level spectrum contained two dominant peaks for $\mathrm{Cr}(\mathrm{BE}$ at $573.80 \mathrm{eV})$ and $\mathrm{Cr}_{2} \mathrm{O}_{3}(\mathrm{BE}$ at $575.90 \mathrm{eV})$ in Figure $9 \mathrm{c}$ and $\mathrm{d}$, respectively. The most noticeable difference between the abiotic coupons and the $P$. aeruginosa coupons was the presence of $\mathrm{Cr}^{6+}$ beneath the biofilm and a higher relative portion of $\mathrm{Cr}(\mathrm{OH})_{3}(\mathrm{BE}$ at $586.8 \mathrm{eV})$.

\section{Discussion}

HDSSs exhibit a high level of corrosion resistance in most environments. Kim et al. ${ }^{2}$ reported that UNS S32707 HDSS is defined as a highly alloyed DSS with a PREN in excess of 45. The 2707 HDSS coupons in this work had a PREN value of 49. This is due to its high Cr content and elevated Mo and Ni levels, which are beneficial in acid and high chloride environments. Furthermore, the well-balanced composition and defect-free microstructure are useful for structural stability and corrosion resistance. Despite its superior chemical corrosion resistance, however, the experimental data in this work demonstrated that 2707 HDSS was not completely immune to the MIC by the $P$. aeruginosa biofilm.

The electrochemical results revealed that the corrosion rate of 2707 HDSS significantly increased in the P. aeruginosa broth after 14 days compared to the abiotic medium. In Figure $2 \mathrm{a}$, a decrease of $\mathrm{E}_{\text {ocp }}$ was observed in both the abiotic medium and the P. aeruginosa broth in the initial $24 \mathrm{~h}$. Afterwards, the biofilm completed the coverage of the coupon surface, $\mathrm{E}_{\text {ocp }}$ became relatively stable ${ }^{36}$. However, the biotic $\mathrm{E}_{\mathrm{ocp}}$ was at a much higher level than the abiotic $\mathrm{E}_{\mathrm{ocp}}$. It is reasonable to believe that the difference was due to the formation of the P. aeruginosa biofilm. In Figure $2 d$, the $\mathrm{i}_{\text {corr }}$ value of $2707 \mathrm{HDSS}$ reached $0.627 \mu \mathrm{A} \mathrm{cm}^{-2}$ in the presence of P. aeruginosa, one 

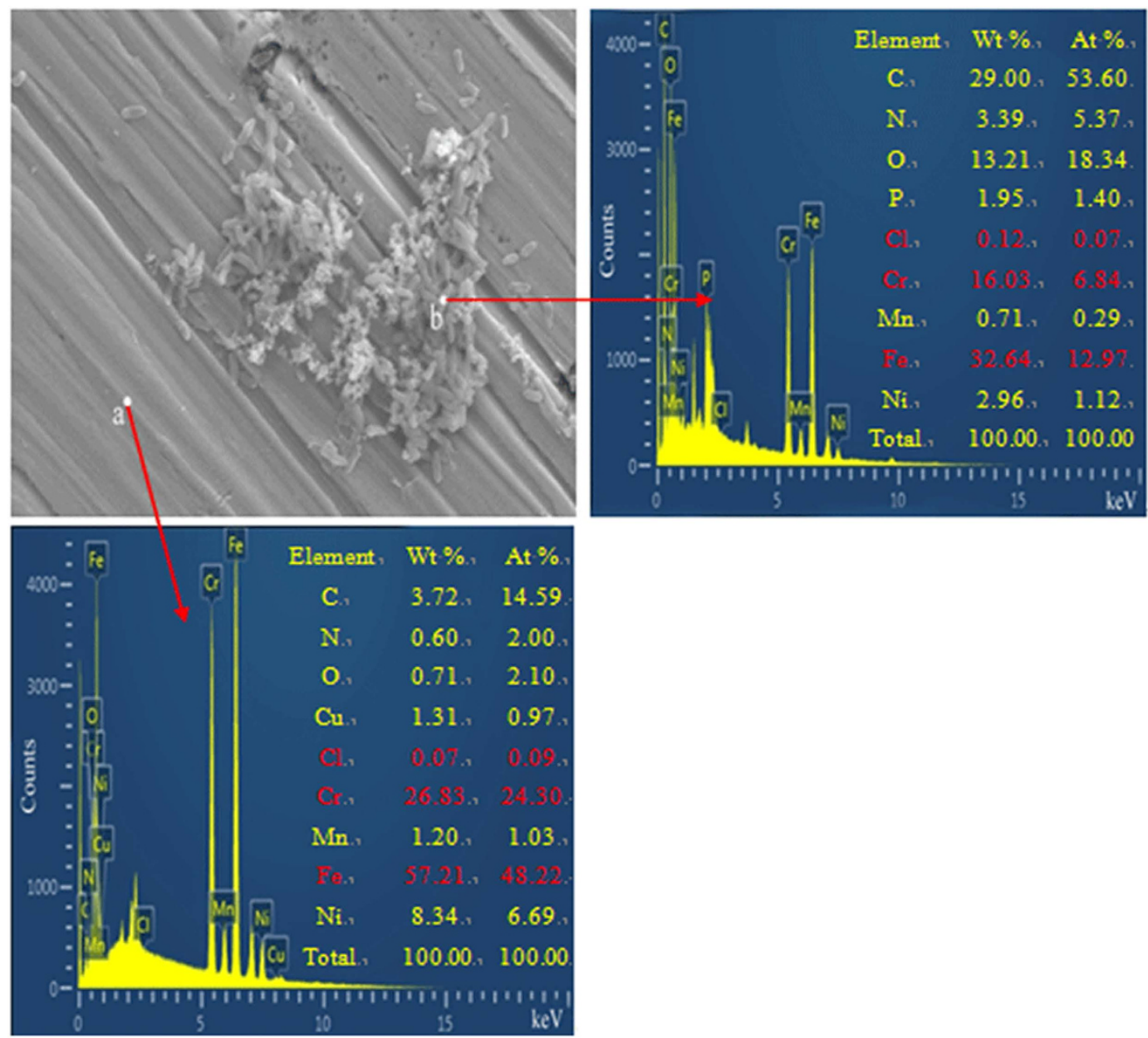

Figure 6. Results of EDS analysis of the 2707 HDSS surface after exposure to $P$. aeruginosa for 14 days.

order of magnitude higher than that for the abiotic control $\left(0.063 \mu \mathrm{A} \mathrm{cm}^{-2}\right)$, which was consistent with the $\mathrm{R}_{\mathrm{ct}}$ values measured by EIS. In the first few days, the impedance value increased in the $P$. aeruginosa broth due to the attachment of $P$. aeruginosa cells and the formation of the biofilm. However, the impedance then decreased when the biofilm fully covered the coupon surface. The protective layer was first attacked because of the formation of the biofilm and metabolites of the biofilm. Consequently, the corrosion resistance decreased with time and the $P$. aeruginosa attachment caused the localized corrosion. The tendency in the abiotic medium was different. The corrosion impedance of the abiotic control was much higher than the corresponding value of the coupon exposed to the P. aeruginosa broth. Furthermore, for the abiotic samples, the $\mathrm{R}_{\mathrm{ct}}$ value of $2707 \mathrm{HDSS}$ reached $489 \mathrm{k} \Omega \mathrm{cm}^{2}$ on the $14^{\text {th }}$ day, fifteen times larger than that in the presence of $P$. aeruginosa $\left(32 \mathrm{k} \Omega \mathrm{cm}^{2}\right)$. Thus, 2707 HDSS possessed excellent corrosion resistance in the sterile environment, but it was not immune to the MIC attack by the P. aeruginosa biofilm.

These results were also observed from the polarization curves in Figure 2b. The anodic branch was attributed to the formation of $P$. aeruginosa biofilm and the metal oxidation reaction. Meanwhile the cathodic reaction was the reduction of oxygen. The presence of $P$. aeruginos a greatly increased the corrosion current density, which was approximately one order of magnitude higher than the abiotic control. It suggested that the P. aeruginosa biofilm increased the localized corrosion of $2707 \mathrm{HDSS}$. Yuan et al..$^{29}$ found that the $70 / 30 \mathrm{Cu}-\mathrm{Ni}$ alloy corrosion current density increased under the attack of a $P$. aeruginosa biofilm. It could be due to the $P$. aeruginosa biofilm's biocatalysis of the reduction of oxygen ${ }^{37}$. This observation could explain the MIC of 2707 HDSS in this work as well. It was also possible that the aerobic biofilm made oxygen less available underneath it. Thus, the failure to repassivate the metal surface by oxygen could be a contributing factor in the MIC in this work.

Dickinson et al. ${ }^{38}$ proposed that the rates of chemical and electrochemical reactions can be directly affected by the metabolic activities of the sessile bacteria on a coupon surface and the nature of corrosion products. As seen in Figure 5 and Table 5, both the cell number and biofilm thickness decreased after 14 days. This can be reasonably explained that after 14 days, most of the sessile cells on the 2707 HDSS surface were dead due to the exhaustion of the nutrients in the 2216E medium or the toxic metal ions released from the 2707 HDSS matrix. This was a limitation of batch experiments.

In this work, the $P$. aeruginosa biofilm promoted the localized depletion of $\mathrm{Cr}$ and $\mathrm{Fe}$ underneath the biofilm on the 2707 HDSS surface (Figure 6). In Table 6, compared with sample C, there was a decrease of Fe and $\mathrm{Cr}$ in sample $\mathrm{D}$, indicating that dissolution $\mathrm{Fe}$ and $\mathrm{Cr}$ caused by the P. aeruginosa biofilm continued beyond the first 7 


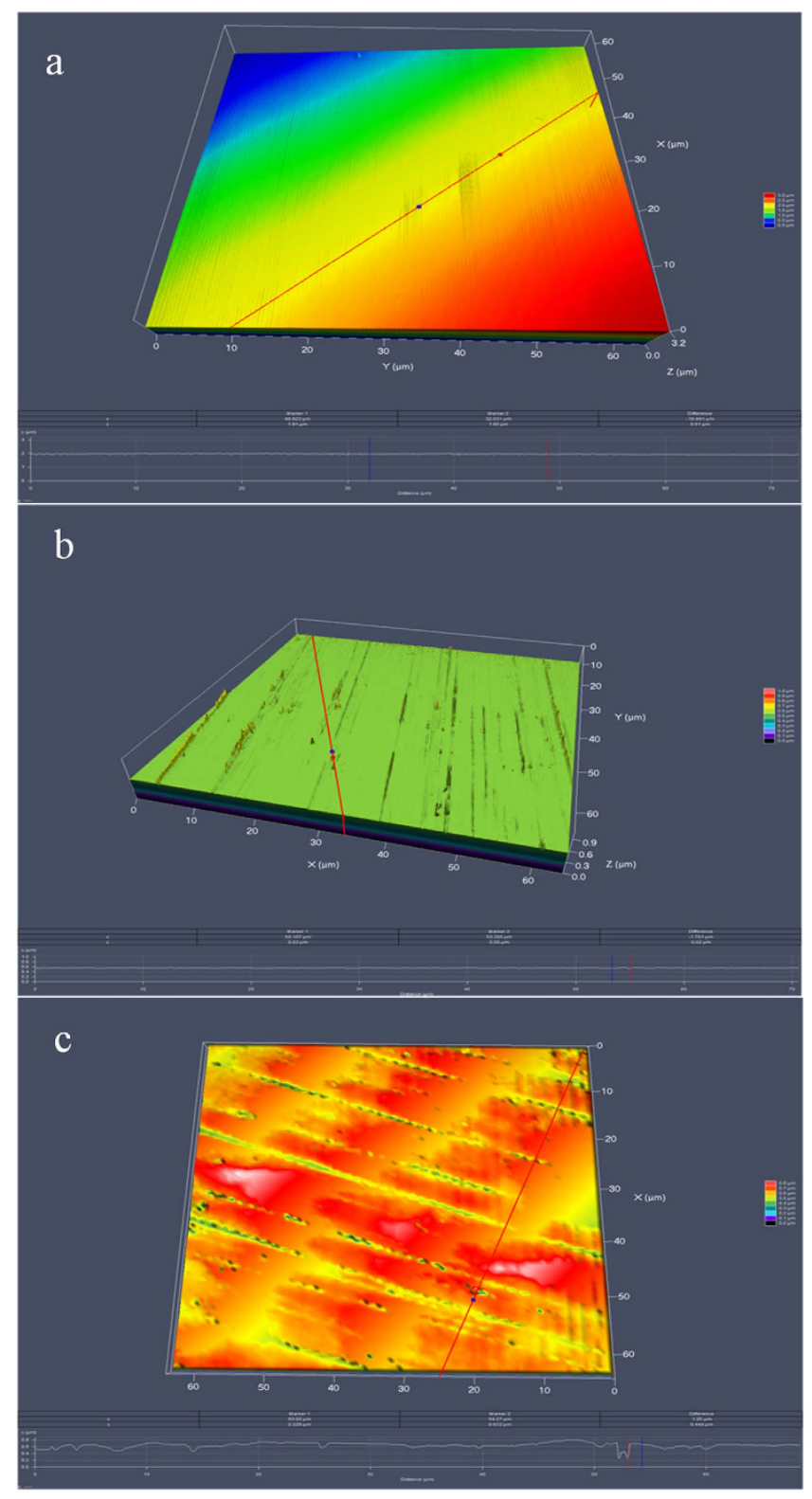

Figure 7. CLSM analysis of pits on coupon surfaces: (a) before exposure, (b) in the abiotic medium for 14 days, and (c) in the P. aeruginosa broth for 14 days.

days. The $2216 \mathrm{E}$ medium was used to simulate the marine environment. It contained $17700 \mathrm{ppm}^{-}$, comparable to that in the natural seawater. The presence of $17700 \mathrm{ppm} \mathrm{Cl}^{-}$was the main reason responsible for the decrease of $\mathrm{Cr}$ from the 7-day and 14-day abiotic samples analyzed by XPS. Compared with the P. aeruginosa coupons, the dissolution of $\mathrm{Cr}$ in abiotic coupons was much smaller due to the strong $\mathrm{Cl}^{-}$resistance of $2707 \mathrm{HDSS}$ in an abiotic environment. Figure 9 shows that the presence of $\mathrm{Cr}^{6+}$ in the passivation film. It might be involved in the removal of Cr from the steel surface by the P. aeruginosa biofilm as suggested by Chen and Clayton ${ }^{39}$.

The $\mathrm{pH}$ values of the culture medium before and after incubation were 7.4 and 8.2 , respectively, due to bacterial growth. Thus, underneath the $P$. aeruginosa biofilm, organic acid corrosion was unlikely a contributing factor in this work due to the relatively high $\mathrm{pH}$ values in the bulk medium. The $\mathrm{pH}$ value of the abiotic control medium didn't change significantly (from the initial 7.4 to the final 7.5) in the 14-day test duration. The increase of $\mathrm{pH}$ in the inoculated medium after incubation was due to the metabolic activities of P. aeruginosa, which was found to have the same impact on $\mathrm{pH}$ in the absence of coupons.

As shown in Figure 7, the maximum pit depth caused by the $P$. aeruginosa biofilms was $0.69 \mu \mathrm{m}$, which was much larger than that in the abiotic medium $(0.02 \mu \mathrm{m})$. This was consistent with the electrochemical data above. The $0.69 \mu \mathrm{m}$ pit depth was more than ten times smaller than the $9.5 \mu \mathrm{m}$ value reported for 2205 DSS under the same conditions ${ }^{40}$. These data proved that 2707 HDSS exhibited a better MIC resistance compared with 2205 DSS. This should not be a surprise because 2707 HDSS has a higher Cr level that offers more durable passivity, making 

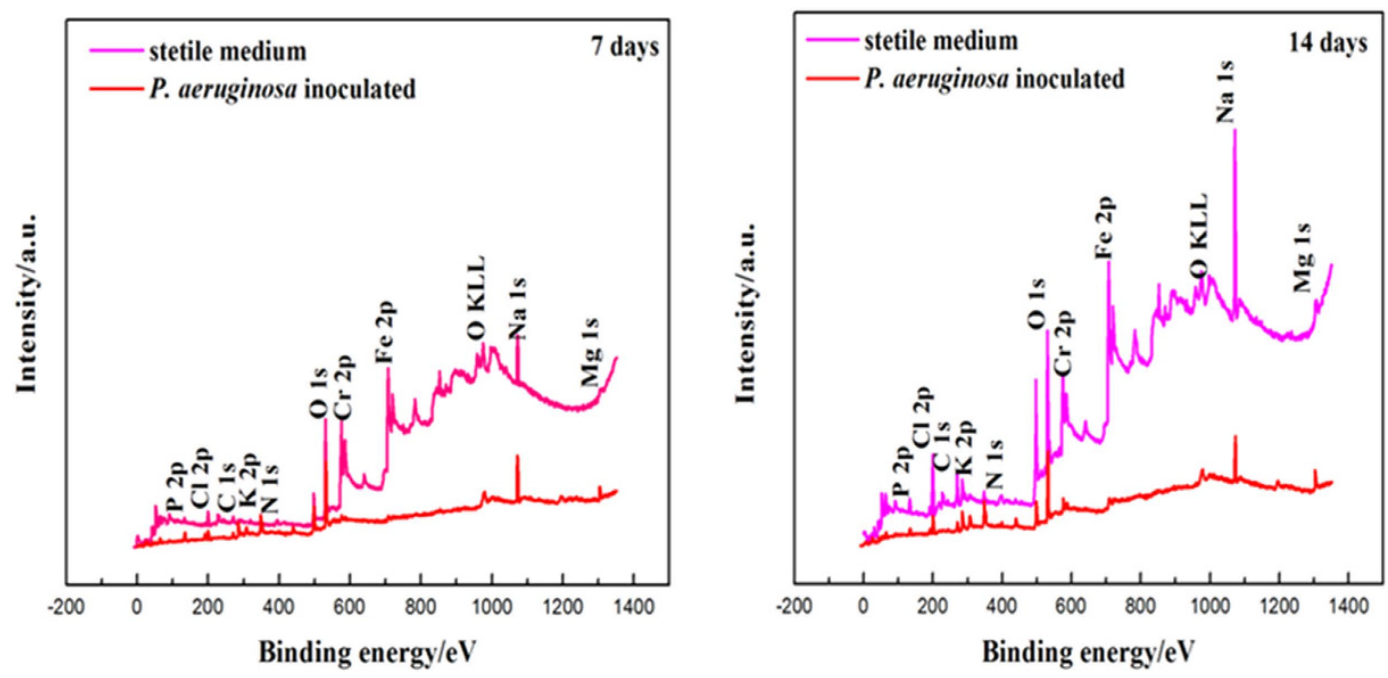

Figure 8. The wide XPS spectra for the surfaces of 2707 HDSS coupons in the both media for 7 days and 14 days, respectively.

\begin{tabular}{|l|c|c|c|c|c|c|c|c|}
\hline \multirow{2}{*}{ Sample } & \multicolumn{7}{|c|}{ Atomic percent (\%) } \\
\cline { 2 - 9 } & $\mathbf{C l}$ & $\mathbf{C}$ & $\mathbf{N}$ & $\mathbf{O}$ & $\mathbf{C r}$ & $\mathbf{F e}$ & $\mathbf{N a}$ & $\mathbf{M g}$ \\
\hline A & 4.59 & 38.81 & 5.45 & 36.67 & 3.69 & 1.82 & 7.78 & 0.22 \\
\hline B & 7.39 & 42.46 & 5.30 & 29.64 & 2.95 & 1.30 & 9.65 & 0.75 \\
\hline C & 6.39 & 58.93 & 5.76 & 23.70 & 0.51 & 0.39 & 3.56 & 0.43 \\
\hline D & 2.62 & 56.95 & 5.35 & 28.71 & 0.21 & 0.16 & 5.64 & 0.36 \\
\hline
\end{tabular}

Table 6. Relative atomic percent (\%) of the main constituents on the surface of 2707 HDSS with and without exposure to $P$. aeruginosa: (A) in the abiotic medium for 7 days, (B) in the abiotic medium for 14 days, (C) in the inoculated medium for 7 days, and (D) in the inoculated medium for 14 days.

it more difficult for $P$. aeruginosa to depassivate and initiate pitting corrosion due to the balanced phase structure without harmful secondary precipitates ${ }^{41}$.

In conclusion, MIC pitting corrosion was found on the surface of 2707 HDSS in the P. aeruginosa broth compared to negligible pitting in the abiotic medium. This work demonstrated that 2707 HDSS had much better MIC resistance than 2205 DSS, but was not completely immune to MIC due to the $P$. aeruginosa biofilm. These findings are useful in the selection of a suitable stainless steel for the marine environment and in the estimation of service life span.

\section{Methods}

Coupon preparation. The coupons of 2707 HDSS were provided by School of Metallurgy, Northeastern University (NEU) in Shenyang, China. The elemental composition of 2707 HDSS was shown in Table 1, which was analyzed by the Department of Materials Analysis and Testing of NEU. All specimens were solution-treated at $1180^{\circ} \mathrm{C}$ for $1 \mathrm{~h}$. Prior to the corrosion tests, coin-shaped $2707 \mathrm{HDSS}$ with a top exposed surface area of $1 \mathrm{~cm}^{2}$ were polished to 2000 grit with silicon carbide papers, and then further polished with a $0.05 \mu \mathrm{m}_{2} \mathrm{O}_{3}$ powder suspension. The side and bottom surface were protected by an inert paint. After drying, the coupons were rinsed with sterile deionized water, and sterilized with $75 \%(\mathrm{v} / \mathrm{v})$ ethanol for $0.5 \mathrm{~h}$. They were then air dried under ultraviolet (UV) light for $0.5 \mathrm{~h}$ before use.

Bacterial strain and cultivation. The marine P. aeruginosa MCCC 1A00099 strain was purchased from the Marine Culture Collection of China (MCCC), Xiamen, China. The marine 2216E liquid medium (Qingdao Hope Bio-technology Co., Qingdao, China) was used to culture the P. aeruginosa at $37^{\circ} \mathrm{C}$ aerobically in $250 \mathrm{ml}$ flasks and in a $500 \mathrm{ml}$ electrochemical glass cell. The culture medium contained $(\mathrm{g} / \mathrm{L}): 19.45 \mathrm{NaCl}, 5.98 \mathrm{MgCl}_{2}, 3.24 \mathrm{Na}_{2} \mathrm{SO}_{4}$, $1.8 \mathrm{CaCl}_{2}, 0.55 \mathrm{KCl}, 0.16 \mathrm{Na}_{2} \mathrm{CO}_{3}, 0.08 \mathrm{KBr}, 0.034 \mathrm{SrCl}_{2}, 0.08 \mathrm{SrBr}_{2}, 0.022 \mathrm{H}_{3} \mathrm{BO}_{3}, 0.004 \mathrm{NaSiO}_{3}, 0.0024 \mathrm{NaF}$, $0.0016 \mathrm{NH}_{4} \mathrm{NO}_{3}, 0.008 \mathrm{NaH}_{2} \mathrm{PO}_{4}, 5.0$ peptone, 1.0 yeast extract, and 0.1 ferric citrate. It was autoclave-sterilized at $121^{\circ} \mathrm{C}$ for $20 \mathrm{~min}$ prior to inoculation. A hemocytometer under a light microscope at $400 \times$ magnification was used to enumerate sessile and planktonic cells. The initial planktonic $P$. aeruginosa cell concentration immediately after inoculation was approximately $10^{6} \mathrm{cells} / \mathrm{ml}$. 

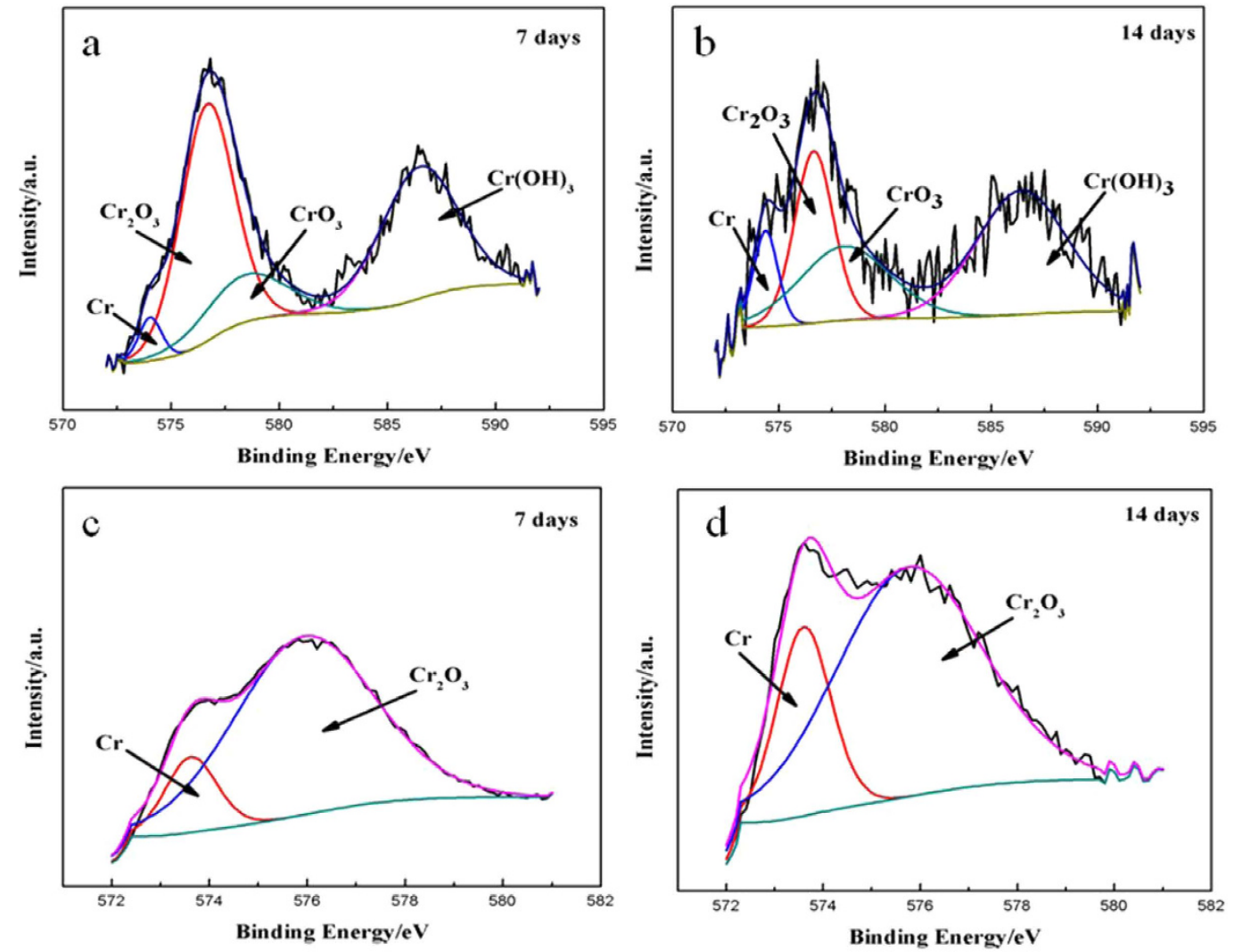

Figure 9. The high resolution XPS spectra of Cr 2p for 2707 HDSS: (a) with exposure to P. aeruginosa for 7 days, (b) with exposure to $P$. aeruginosa for 14 days, (c) in the abiotic medium for 7 days, and (d) in the abiotic medium for 14 days.

Electrochemical test procedures. Electrochemical tests were carried out in a classical three-electrode glass cell with a culture medium volume of $500 \mathrm{ml}$. A platinum sheet and a saturated calomel electrode (SCE) connected to the reactor via a Luggin capillary filled with a salt bridge as the counter and reference electrodes, respectively. To create a working electrode, a rubber-coated copper wire was connected to each coupon and covered with epoxy resin leaving an exposed one-sided surface area of approximately $1 \mathrm{~cm}^{2}$ for this working electrode. During electrochemical measurements, samples were placed in the 2216E medium, and maintained at a constant incubation temperature $\left(37^{\circ} \mathrm{C}\right)$ in a water bath. The OCP, LPR, EIS and potential dynamic polarization data were measured with an Autolab potentiostat (Reference $600^{\mathrm{TM}}$, Gamry Instruments, Inc., USA). LPR tests were recorded at a scan rate of $0.125 \mathrm{mV} \mathrm{s}^{-1}$ in the range of -5 and $5 \mathrm{mV}$ versus $E_{\text {ocp }}$, and the sampling frequency was $1 \mathrm{~Hz}$. EIS was performed under a steady-state $\mathrm{E}_{\text {ocp }}$ using a $5 \mathrm{mV}$ applied voltage at sinusoidal wave in a frequency range of 0.01 to $10,000 \mathrm{~Hz}$. Before the potential scan, the electrodes were in the open circuit mode until a steady free corrosion potential value reached ${ }^{42}$. The polarization curves were then run at a scan rate of $0.166 \mathrm{mV} / \mathrm{s}$ from -0.2 to $1.5 \mathrm{~V}$ vs. $\mathrm{E}_{\text {ocp }}$. Each test was repeated three times with and without P. aeruginosa.

Surface analysis. The coupons for the metallographic analysis were mechanically polished with wet SiC paper of 2000 grit, and then further polished with a $0.05 \mu \mathrm{m} \mathrm{Al}_{2} \mathrm{O}_{3}$ powder suspension to enable optical observations to be made. Metallographic analysis was carried out using an optical microscopy. The coupons were etched with a $10 \mathrm{wt} . \%$ potassium hydroxide solution ${ }^{43}$.

After incubation, a coupon was washed with a phosphate buffer saline (PBS) solution ( $\mathrm{pH} 7.4 \pm 0.2)$ three times and then fixed with $2.5 \%(\mathrm{v} / \mathrm{v})$ glutaraldehyde for $10 \mathrm{~h}$ to fix the biofilm. It was subsequently dehydrated with a graded series $(50 \%, 60 \%, 70 \%, 80 \%, 90 \%, 95 \%$ and $100 \%$ v/v) of ethanol before air-drying. Finally, the coupon surface was sputter-coated with a gold film to provide conductivity for SEM observation ${ }^{44}$. SEM images focused on spots with the most sessile P. aeruginosa cells on each coupon surface. The EDS analysis was undertaken to find the chemical elements. A Zeiss confocal laser scanning microscope (CLSM) (LSM 710, Zeiss, Germany) was used to measure the pit depth. To observe the corrosion pits underneath a biofilm, the coupon was first cleaned according to the Chinese National Standards (CNS) GB/T4334.4-2000 to remove the corrosion products and biofilms on the coupon surface.

An X-ray photoelectron spectroscopy (XPS, ESCALAB250 surface analysis system, Thermo VG, USA) anal-

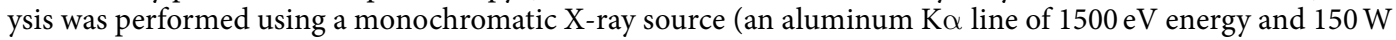
power) within the wide binding energy range of $0-1350 \mathrm{eV}$ under standard conditions. The high resolution spectra were recorded using $50 \mathrm{eV}$ pass energy and $0.2 \mathrm{eV}$ step. 
Bacterial stain assay. The coupons after incubation were taken out and gently rinsed with PBS (pH $7.4 \pm 0.2$ ) for $15 \mathrm{~s}^{45}$. In order to observe the bacterial viability of the biofilms on the coupon, LIVE/DEAD BacLight Bacterial Viability Kits (Invitrogen, Eugene, OR, USA) were used to stain the biofilms. The kits have two fluorescent dyes, the green-fluorescent SYTO-9 dye and the red-fluorescent propidium iodide (PI) dye. Under CLSM, the dots with fluorescent green and red represented the live and dead cells, respectively. When staining, $1 \mathrm{ml}$ mixture containing $3 \mu \mathrm{l}$ SYTO- 9 and $3 \mu \mathrm{l}$ PI solutions were incubated for $20 \mathrm{~min}$ in the dark at room temperature $\left(23^{\circ} \mathrm{C}\right)$. After that, a Nikon CLSM machine (C2 Plus, Nikon, Japan) was used to observe the stained sample at at two wave lengths ( $488 \mathrm{~nm}$ for living cells and $559 \mathrm{~nm}$ for dead cells). The biofilm thickness was measured in the 3 -D scanning mode.

\section{References}

1. Zanotto, F., Grassi, V., Balbo, A., Monticelli, C. \& Zucchi, F. Stress corrosion cracking of LDX 2101 duplex stainless steel in chloride solutions in the presence of thiosulphate. Corros. Sci. 80, 205-212 (2014).

2. Kim, S. T., Jang, S. H., Lee, I. S. \& Park, Y. S. Effects of solution heat-treatment and nitrogen in shielding gas on the resistance to pitting corrosion of hyper duplex stainless steel welds. Corros. Sci. 53, 1939-1947 (2011).

3. Shi, X., Avci, R., Geiser, M. \& Lewandowski, Z. Comparative study in chemistry of microbially and electrochemically induced pitting of 316L stainless steel. Corros. Sci. 45, 2577-2595 (2003).

4. Luo, H., Dong, C. F., Li, X. G. \& Xiao, K. The electrochemical behavior of 2205 duplex stainless steel in alkaline solutions with different $\mathrm{pH}$ in the presence of chloride. Electrochim. Acta. 64, 211-220 (2012).

5. Little, B. J., Lee, J. S. \& Ray, R. I. The influence of marine biofilms on corrosion: A concise review. Electrochim. Acta. 54, 2-7 (2008).

6. Liang, C., Wang, H. \& Huang, N. Effects of Sulphate-reducing bacteria on corrosion behaviour of 2205 duplex stainless steel. J. Iron. Steel. Res. 21, 444-450 (2014).

7. Jeon, S. H., Kim, H. J. \& Park, Y. S. Effects of inclusions on the precipitation of chi phases and intergranular corrosion resistance of hyper duplex stainless steel. Corros. Sci. 87, 1-5 (2014).

8. Deng, B. et al. Effect of thermal cycles on the corrosion and mechanical properties of UNS S31803 duplex stainless steel. Corros. Sci. 51, 2969-2975 (2009).

9. Kim, J. S. et al. Mechanism of localized corrosion and phase transformation of tube-to-tube sheet welds of hyper duplex stainless steel in acidified chloride environments. Mater. Trans. 12, 2166-2174 (2012).

10. Deng, B. et al. Evaluation of localized corrosion in duplex stainless steel aged at $850^{\circ} \mathrm{C}$ with critical pitting temperature measurement. Electrochim. Acta. 54, 2790-2794 (2009).

11. Pilhagen, J., Sieurin, H. \& Sandstrom, R. Fracture toughness of a welded super duplex stainless steel. Mat. Sci. Eng. A-Struct. 606, 40-45 (2014).

12. Lee, J. S., Fushimi, K., Nakanishi, T., Hasegawa, Y. \& Park, Y. S. Corrosion behavior of ferrite and austenite phases on super duplex stainless steel in a modified green-death solution. Corros. Sci. 89, 111-117 (2014).

13. Kim, H. J., Jeon, S. H., Kim, S. T. \& Park, Y. S. Influence of the shielding gas composition on the passive film and erosion corrosion of tube-to-tube sheet welds of hyper duplex stainless steel. Corros. Sci. 91, 140-150 (2015).

14. Xu, D., Li, Y., Song, F. \& Gu, T. Laboratory investigation of microbiologically influenced corrosion of C1018 carbon steel by nitrate reducing bacterium Bacillus licheniformis. Corros. Sci. 77, 385-390 (2013).

15. Alabbas, F. M. et al. Influence of sulfate reducing bacterial biofilm on corrosion behavior of low-alloy, high-strength steel (API-5L X80). Int. Biodeterior. Biodegrad. 78, 34-42 (2013).

16. Hamzah, E., Hussain, M. Z., Ibrahim, Z. \& Abdolahi, A. Influence of Pseudomonas aeruginosa bacteria on corrosion resistance of 304 stainless steel. Corros. Eng. Sci. Techn. 48, 116-120 (2013).

17. Xu, D. \& Gu, T. Carbon source starvation triggered more aggressive corrosion against carbon steel by Desulfovibrio vulgaris biofilm. Int. Biodeter. Biodegr. 91, 74-81 (2014).

18. Zhang, P., Xu, D., Li, Y., Yang, K. \& Gu, T. Electron mediators accelerate the microbiologically influenced corrosion of 304 stainless steel by Desulfovibrio vulgaris biofilm. Bioelectrochemistry. 101, 14-21 (2015).

19. Venzlaff, H. et al. Accelerated cathodic reaction in microbial corrosion of iron due to direct electron uptake by sulfate-reducing bacteria. Corros. Sci. 66, 88-96 (2013).

20. Enning, D. et al. Marine sulfate-reducing bacteria cause serious corrosion of iron under electroconductive biogenic mineral crust: Microbial iron corrosion under electroconductive crust. Environ. Microbiol. 14, 1772-1787 (2012).

21. Xu, C., Zhang, Y., Cheng, G. \& Zhu, W. Pitting corrosion behavior of 316L stainless steel in the media of sulphate-reducing and ironoxidizing bacteria. Mater. Charact. 59, 245-255 (2008)

22. Shi, X. et al. Comparative study in chemistry of microbially and electrochemically induced pitting of 316L stainless steel. Corros. Sci. 45, 2577-2595 (2003).

23. Mansfeld, F. The interaction of bacteria and metal surfaces. Electrochim. Acta. 52, 7670-7680 (2007).

24. Antony, P. J., Singh Raman, R. K., Mohanram, R. \& Kumar, P. Influence of thermal aging on sulfate-reducing bacteria (SRB)influenced corrosion behaviour of 2205 duplex stainless steel. Corros. Sci. 50, 1858-1864 (2008).

25. Mansouri, H., Alavi, S. A. \& Yari, M. A. Study of Pseudomonas aeruginosa bacteria in microbial corrosion. $2^{\text {nd }}$ International Conference on Chemical, Ecology and Environmental Sciences. Singapore April, 28-29 (2012).

26. Stott, J. F. D. What progress in the understanding of microbially induced corrosion has been made in the last 25 years? A personal view point. Corros. Sci. 35, 667-673 (1993).

27. San, N. O., Nazir, H. \& Donmez, G. Microbially influenced corrosion and inhibition of nickel-zinc and nickel-copper coatings by Pseudomonas aeruginosa. Corros. Sci. 79, 177-183 (2014).

28. Mahat, M. M. et al. A preliminary study on Microbiologically influenced corrosion (MIC) of mild steel by Pseudomonas aeruginosa by using infinite focus microscope (IFM). AIP. Conf. Proc. 1455, 117 (2012).

29. Yuan, S. J., Choong, A. M. F. \& Pehkonen, S. O. The influence of the marine aerobic Pseudomonas strain on the corrosion of 70/30 Cu-Ni alloy. Corros. Sci. 49, 4352-4385 (2007).

30. Yuan, S. Y., Liang, B., Zhao, Y. \& Pehkonen, S. O. Surface chemistry and corrosion behavior of 304 stainless steel in simulated seawater containing inorganic sulphide and sulphate-reducing bacteria. Corros. Sci. 74, 353-366 (2013).

31. Yuan, S. J. et al. Biocorrosion behavior of titanium oxide/butoxide-coated stainless steel. J. Electrochem. Soc. 155, 196-210 (2008).

32. Millard, S. G., Law, D., Bungey, J. H. \& Cairns, J. Environmental influences on linear polarisation corrosion rate measurement in reinforced concrete. NDT. \& E. Int. 34, 409-417 (2001).

33. Zou, Y., Wang, J. \& Zheng, Y. Y. Electrochemical techniques for determining corrosion rate of rusted steel in seawater. Corros. Sci. 53, 208-216 (2011).

34. Mansfeld, F., Liu, G., Xiao, H., Tsai, C. H. \& Little, B. J. The corrosion behavior of copper alloys, stainless steels and titanium in seawater. Corros. Sci. 36, 2063-2095 (1994).

35. Wu, X., Ma, H., Chen, S., Xu, Z. \& Sui, A. General equivalent circuits for faradaic electrode processes under electrochemical reaction control. J. Electrochem. Soc. 146, 1847-1853 (1999). 
36. Moradi, M., Song, Z., Yang, L., Jiang, J. \& He, J. Effect of marine Pseudoalteromonas sp. on the microstructure and corrosion behaviour of 2205 duplex stainless steel. Corros. Sci. 84, 103-112 (2014).

37. Cournet, A., Berge, M., Roques, C., Bergel, A. \& Delia, M. L. Electrochemical reduction of oxygen catalyzed by Pseudomonas aeruginosa. Electrochim. Acta. 55, 4902-4908 (2010).

38. Dickinson, W. H. \& Lewandowski, Z. Electrochemical concepts and techniques in the study of stainless steel ennoblement. Biodegradation. 9, 11-21 (1998).

39. Chen, G. \& Clayton, C. R. The influence of sulfate-reducing bacteria on the passivity of type 317L austenitic stainless steel. J. Electrochem. Soc. 145, 1914-1922 (1998).

40. Xia, J. et al. Laboratory investigation of the microbiologically influenced corrosion (MIC) resistance of a novel Cu-bearing 2205 duplex stainless steel in the presence of an aerobic marine Pseudomonas aeruginosa biofilm. Biofouling. 31, 481-492 (2015).

41. Antony, P. J., Singh Raman, R. K., Raman, R. \& Kumar, P. Role of microstructure on corrosion of duplex stainless steel in presence of bacteria activity. Corros. Sci. 52, 1404-1412 (2010).

42. Atta, N. F., Fekry, A. M. \& Hassaneen, H. M. Corrosion inhibition, hydrogen evolution and antibacterial properties of newly synthesized organic inhibitors on 316L stainless steel alloy in acid medium. Int. J. Hydrogen. Energ. 36, 6462-6471 (2011).

43. Ren, L., Nan, L. \& Yang, K. Study of copper precipitation behavior in a Cu-bearing austenitic antibacterial stainless steel. Mater. Des. 32, 2374-2379 (2011)

44. Wen, J., Zhao, K., Gu, T. \& Raad, I. I. A green biocide enhancer for the treatment of sulfate-reducing bacteria (SRB) biofilms on carbon steel surfaces using glitaraldehyde. Int. Biodeter. Biodegr. 63, 1102-1106 (2009).

45. Jin, Y. et al. The use of new probes and stains for improved assessment of cell viability and extracellular polymeric substances in Candida albicans biofilms. Mycopathologia. 159, 353-360 (2005).

\section{Acknowledgements}

This work was finically supported by the High Technology Research and Development Program of China (No. 2015AA034301), the National Natural Science Foundation (No. 51501203), the National Key Technology Research and Development Program of the Ministry of Science and Technology of China (No. 2012BAE04B01), the Program for New Century University Excellent Talents (No. N130502001), the National Basic Research Program of China (973 Program No. 2014CB643300), the National Environmental Corrosion Platform (NECP), and the "Young Merit Scholars" program of the Institute of Metal Research, Chinese Academy of Sciences.

\section{Author Contributions}

H.L., E.Z. and D.X. designed the experiments and conducted the data analysis; H.L., E.Z., C.Y., D.X., J.X. and H.F. carried out the experiments; H.L., E.Z., D.Z., D.X., Z.J. and K.Y. contributed to the planning and coordination of the project; H.L., E.Z., X.L., D.X. and T.G. wrote and edited the manuscript. All authors participated in discussion about the results and the manuscript.

\section{Additional Information}

Competing financial interests: The authors declare no competing financial interests.

How to cite this article: $\mathrm{Li}, \mathrm{H}$. et al. Microbiologically Influenced Corrosion of 2707 Hyper-Duplex Stainless Steel by Marine Pseudomonas aeruginosa Biofilm. Sci. Rep. 6, 20190; doi: 10.1038/srep20190 (2016).

(c) (i) This work is licensed under a Creative Commons Attribution 4.0 International License. The images unless indicated otherwise in the credit line; if the material is not included under the Creative Commons license, users will need to obtain permission from the license holder to reproduce the material. To view a copy of this license, visit http://creativecommons.org/licenses/by/4.0/ 